\title{
Hydrophilic matrices to be used as bioactive and degradable bone cements
}

\author{
LUCIANO F. BOESEL ${ }^{1,2 *}$, RUI L. REIS ${ }^{1,2}$ \\ ${ }^{1} 3 B^{\prime}$ 's Research Group - Biomaterials, Biodegradables and Biomimetics, University of Minho, \\ Campus of Gualtar, 4710-057, Braga, Portugal \\ E-mail: Ifboesel@dep.uminho.pt \\ ${ }^{2}$ Department of Polymer Engineering, University of Minho, Campus of Azurém, 4800-058, \\ Guimarães, Portugal
}

Two different hydrophilic systems were investigated regarding their suitability to be used as enzymatically degradable and highly bioactive bone cements. They contained either acrylic acid (AA) or 2-hydroxyethyl methacrylate (HEMA) as the hydrophilic monomer. Swelling, degradation, mechanical and bioactivity tests were employed to characterise their behaviour. Although both of the systems were very hydrophilic, only the one containing HEMA was able to form an apatite-like layer on its surface. Moreover, this system could be degraded by amylolytic enzymes at a rate easily controlled by the incorporation of different amounts of enzyme to the formulation, as shown by the evolution of the mechanical properties, weight loss and glucose concentration in the solution. These results show these novel systems have a great potential to induce bone ingrowth inside the pores created during the degradation of the material, therefore establishing a strong interface with the tissue.

\section{(C) 2004 Kluwer Academic Publishers}

\section{Introduction}

Since only weak forces join the cement to the bone (mainly mechanical interlocking due to the penetration of the cement in intertrabecular spaces [1]), it has been widely accepted that novel successful formulations should provide a means of improving this interaction. One way of achieving this goal is the incorporation of highly bioactive particles, which can induce (in vitro) the formation of calcium-phosphate on the surfaces of the matrix polymeric matrix. This phenomenon is an indication that, in vivo, bone ingrowth would occur on the surface of the implanted cement.

However, commercial bone cements, as well as the majority of the experimental cements under investigation $[2,3]$, are hydrophobic, which means that only the particles on their surface are accessible to the physiological solutions; moreover the growing of new bone would also be restricted to the surfaces. Certainly a much stronger interaction would be obtained if the bone was induced to grow also inside the material. For this to occur, it is necessary for the material to be hydrophilic (to uptake water and make the inner particles accessible), degradable (to create empty volume which would be filled by the bone) and highly bioactive.

In the past few years, a novel class of experimental bone cements was developed which comply with all these requirements [4-6]. This was achieved by means of the use of a starch-based blend within the solid component, bioactive glass as a filler and a hydrogelforming monomer as one of the constituents of the liquid component. Previous reports have shown that the swelling kinetics of these so-called hydrophilic bone cements (HBC's) is dependent on the $\mathrm{pH}$ of the surrounding medium [5], that the amount of residual monomer is very low $(<1 \mathrm{~mol} \%)$ [6] and that the molar ratio of monomers used determined the swelling kinetics and its extent [4].

In this study, our objective is to assess the suitability of two different systems as potential candidates for being used as HBC's. Their bioactivity as well as their swelling and degradation behaviour were investigated (in order to identify a matrix where these phenomena are concomitant).

\section{Materials and methods}

Specimens were prepared by adding the solid component to the liquid component. The solid was constituted by a commercially available corn starch/cellulose acetate 50/ $50 \mathrm{wt} \%$ blend (SCA), obtained from Novamont, Italy and by a commercial bioactive glass, Bioglass ${ }^{\circledR}$ 45S5 (US Biomaterials Corp., USA). Additional information on the starch-based polymers that have been proposed for several biomedical applications may be found elsewhere [7-9]. The liquid was constituted by a mixture of acrylic acid (AA, Merck, Germany) and methyl methacrylate

*Author to whom all correspondence should be addressed. 
T A B L E I Formulations prepared and respective nomenclature

\begin{tabular}{|c|c|c|c|c|c|c|c|c|c|}
\hline Formulation & SCA $(\%)$ & Bioglass (\%) & $\mathrm{BPO}(\%)$ & MMA (\%) & $\mathrm{AA}(\%)$ & HEMA (\%) & DMOH (\%) & DMT (\%) & $\alpha$-amylase sol (ml) \\
\hline $\mathrm{A} 00$ & 59.3 & - & 0.765 & 29.1 & 10.5 & - & 0.321 & - & - \\
\hline $\mathrm{C} 00$ & 64.6 & - & 0.466 & - & - & 34.8 & - & 0.174 & - \\
\hline $\mathrm{A}-\mathrm{BG}$ & 29.6 & 29.6 & 0.765 & 29.1 & 10.5 & - & 0.321 & - & - \\
\hline $\mathrm{C}-\mathrm{BG}$ & 29.7 & 29.7 & 0.737 & - & - & 39.6 & - & 0.277 & - \\
\hline S05 & 64.6 & - & 0.466 & - & - & 34.8 & - & 0.174 & 0.05 \\
\hline $\mathrm{S} 10$ & 64.6 & - & 0.466 & - & - & 34.8 & - & 0.174 & 0.10 \\
\hline
\end{tabular}

(MMA, Merck, Germany) or by 2-hydroxyethyl methacrylate (HEMA, Fluka, Germany), which were used as received. Benzoyl peroxide powder (BPO, Merck, Germany) was used as the polymerisation initiator. $N$ dimethyl-p-toluidine (DMT, Aldrich, Germany) or $\mathrm{N}$ dimethylaminobenzyl alcohol (DMOH, prepared at our labs according to Elvira et al. [10]) were used as the activator of the initiator. Thermostable, liquid $\alpha$-amylase $(22750 \mathrm{U} / \mathrm{ml})$ was obtained from Genencor International, USA. The different formulations prepared, as well as their nomenclature, are summarised in Table I.

Compressive tests were carried out at room temperature on an Instron 4505 Universal Mechanical Testing Machine using a load cell of $50 \mathrm{kN}$. A minimum of five specimens were tested for each experimental condition. The specimens were tested either after storage at $23^{\circ} \mathrm{C}$ and $55 \% \mathrm{RH}$ or after one or two weeks of immersion in a phosphate-buffered saline (PBS) maintained at $37^{\circ} \mathrm{C}$. In this case, they were tested after a period of drying at $23^{\circ} \mathrm{C}$ and $55 \% \mathrm{RH}$ for equilibration of their moisture content. Specimens were cylinders with $6 \mathrm{~mm}$ diameter and $12 \mathrm{~mm}$ height. The crosshead speed was $20 \mathrm{~mm} / \mathrm{min}$. Tests were carried out up to specimens failure or until $60 \%$ reduction in specimen height.

The water-uptake and degradation of the prepared bone cement formulations was studied over a period of 84 days. Specimens (identical to the ones used for the compression tests) were immersed in isotonic saline solution (ISS: $0.154 \mathrm{M} \mathrm{NaCl}$ aqueous solution at $\mathrm{pH} 7.4$ ) or PBS at a ratio 1:15 (specimen mass: solution volume). The specimens were removed at regular intervals, being taken out of the solution, rinsed with distilled water, blotted on filter paper to remove surface solution/water and immediately weighed. They were then dried at controlled conditions $\left(23^{\circ} \mathrm{C}, 55 \% \mathrm{RH}\right)$ to constant weight in order to determine the weight loss (WL). Water uptake (WU) was calculated using the following equation:

$$
\mathrm{WU}_{t}=\left[\left(m_{t}-m_{0}\right) / m_{0}\right] * 100
$$

where $m_{t}$ is the mass of the specimen at time $t$ (days) and $m_{0}$ is the mass prior to immersion $(t=0)$. WL was calculated as follows:

$$
\mathrm{WL}_{t}=\left[\left(m_{f, t}-m_{0}\right) / m_{0}\right] * 100
$$

where $m_{f, t}$ is the final mass of the specimen removed after $t$ days of immersion in the ISS or PBS.

Enzyme activity was determined by measuring the concentration of reducing sugars liberated into the solution using the dinitrosalicylic acid (DNS) method [11]; briefly, after reaction of this compound with the glucose contained in the degradation solutions, the new compound formed was quantitatively determined with an UV-Vis spectrophotometer at a wavelenght of $540 \mathrm{~nm}$.

The bioactive behaviour of the prepared bone cement formulations was studied over a period of 30 days. Specimens (identical to the ones used for the compression tests) were immersed immediately after preparation in a simulated body fluid (SBF: $142.0 \mathrm{mM} \mathrm{Na}^{+}$, 5.0 $\mathrm{mM} \mathrm{K}^{+}, \quad 2.5 \mathrm{mM} \mathrm{Ca}^{2+}, \quad 1.5 \mathrm{mM} \mathrm{Mg}^{2+}$, $147.8 \mathrm{mM} \mathrm{Cl}^{-}, \quad 4.2 \mathrm{mM} \mathrm{HCO}_{3}^{-}, \quad 1.0 \mathrm{mM} \mathrm{HPO}_{4}^{2+}$, $0.5 \mathrm{mM} \mathrm{SO}_{4}^{2-}$ ). The specimens were removed at regular intervals of seven, 14 and 30 days, being taken out of the solution, rinsed with distilled water, dried at room temperature and then gold-coated by ion sputtering and subsequently observed in a Leica Cambridge S360 scanning electron microscope (SEM).

\section{Results and discussion}

The kinetics and extent of water uptake have influence on both the bioactivity and the enzymatic degradation. Fig. 1 shows the swelling behaviour of both systems: both swell quickly in the first week and later on attain an equilibrium value of water concentration around 50$55 \mathrm{wt} \%$. As the AA is much more hydrophilic than HEMA, the A00 sorbs equivalent (or even more) amounts of water even when AA is only $10.5 \%$ of the material, while HEMA is present as the only acrylic monomer on the formulation (therefore at a concentration of $35 \%$ ). However, the similar levels of water uptake will allow a fair comparison between the two materials.

An important requirement for the successful application of these systems is, as outlined before, the existence of a strong bioactive behaviour. The filler added to investigate the ability of the matrices to allow the in vitro

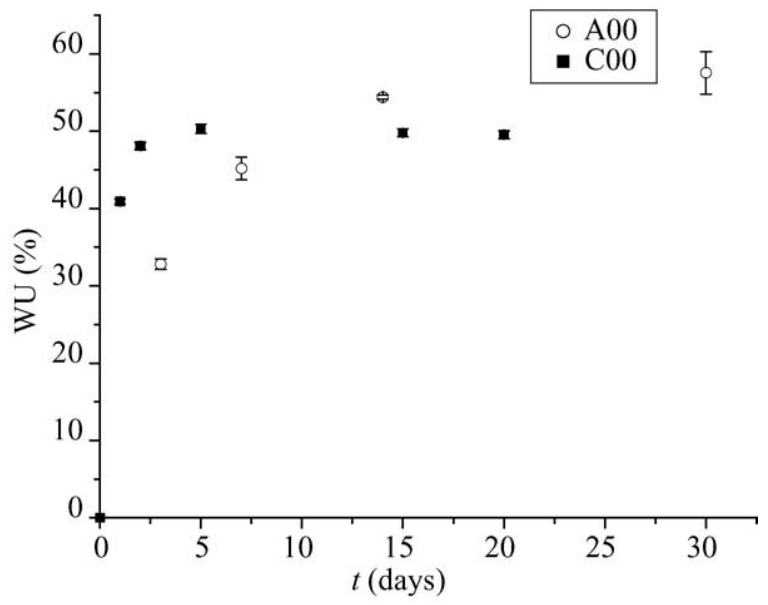

Figure 1 Water uptake (WU) of the base formulations containing AA (A00) or HEMA (C00) immersed in ISS. 

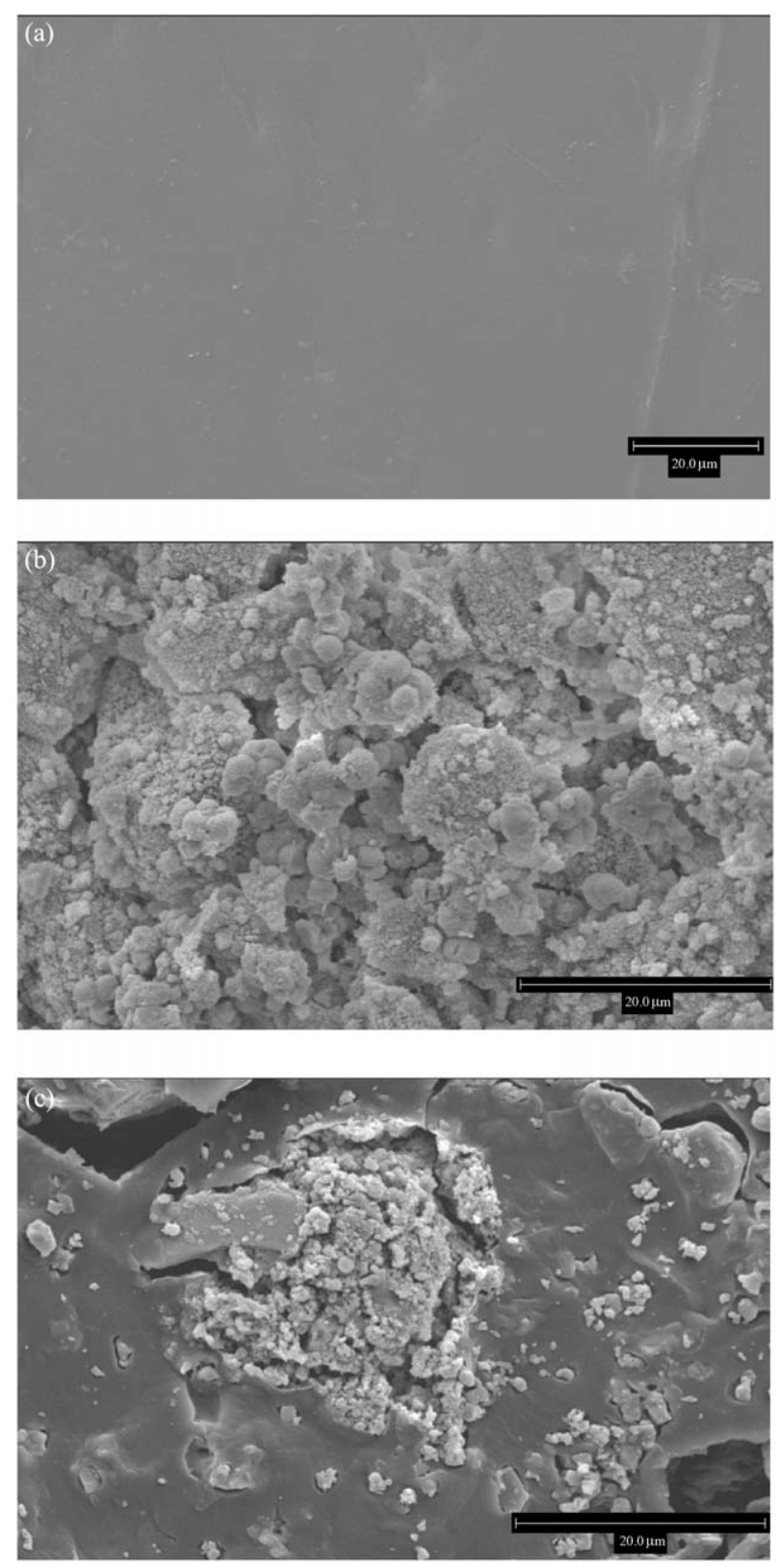

Figure 2 SEM micrographs of the surface of specimens immersed in SBF. (a) Polyethylene (control sample), 14 days of immersion. (b) C$\mathrm{BG}$, seven days of immersion. (c) A-BG, 30 days of immersion.

formation of an apatite layer was Bioglass ${ }^{\circledR} 45 \mathrm{~S} 5$, a well-known highly reactive glass. Fig. 2(a)-(c) shows the surface of composites A-BG and C-BG after immersion in $\mathrm{SBF}$, as well as the surface of a control (non-bioactive) sample (polyethylene). Despite the high hydrophilicity of both systems, only C-BG showed a clearly bioactive behaviour. Nuclei of calcium phosphates were observed in the first days after immersion (data not shown) and a dense layer covering all the surface was present after seven days of immersion (Fig. 2(b)). For A-BG, on the other hand, only nuclei surrounding the glass particles were observed, with the matrix being uncovered even after 30 days of immersion (Fig. 2(c)). The reason for this opposite behaviour was further investigated and published elsewhere [12]. Briefly, the unreacted AA released to the solution presents an inhibitory effect on the apatite formation; therefore low reactive materials do not induce any apatite formation, while highly reactive glasses (such
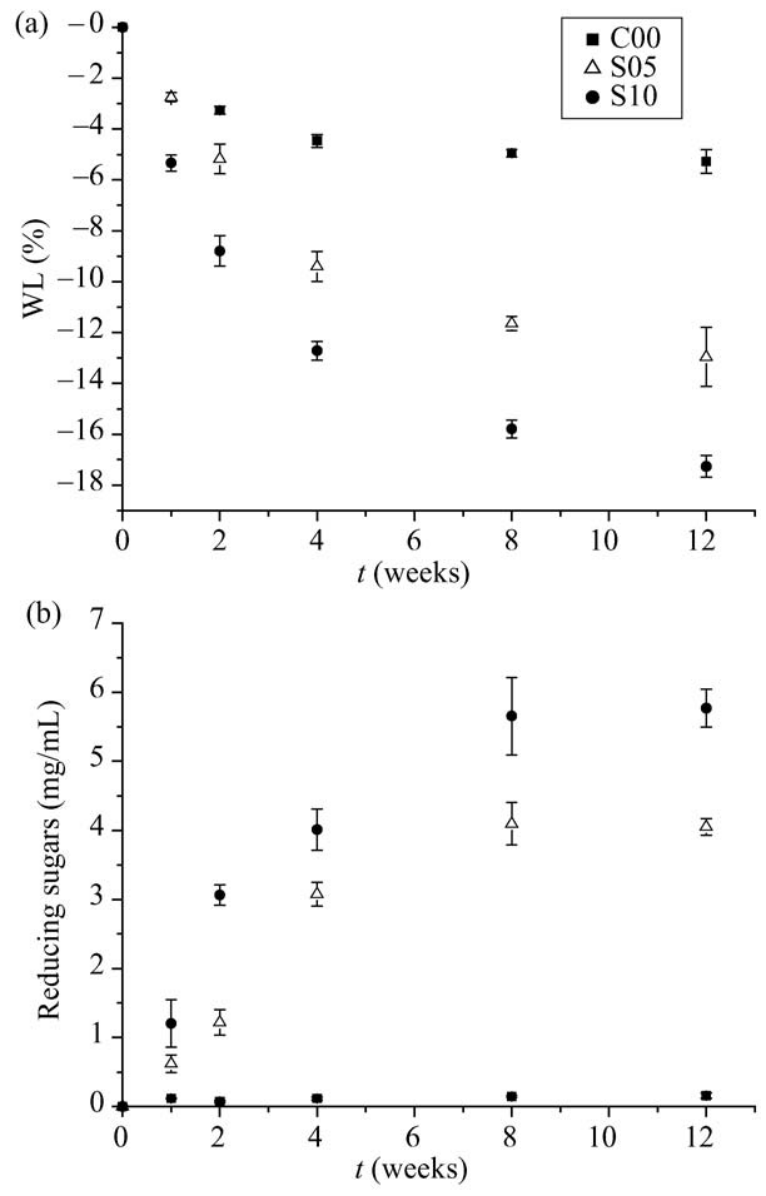

Figure 3 Weight loss (a) and enzyme activity (b) of formulations containing HEMA and different amounts of thermostable $\alpha$-amylase. Enzyme activity is measured as the concentration of reducing sugars released into the solution.

as the one used in the present study) only induce the formation of nuclei after long immersion times [12].

In view of these results, only the system containing HEMA was selected for the enzymatic degradation tests. Fig. 3(a) and (b) shows the strong effect of the incorporated enzyme on the degradation of the cements. Higher amounts of $\alpha$-amylase in the cement, as well as longer degradation times, gave rise to higher extent of degradation, comproved by a higher WL. The similar evolution seen in both figures allows to associate the higher WL to a higher extent of enzymatic hydrolysis of starch molecules, with the consequent release of glucose to the degradation solution.

This phenomenon leads to the formation of a microporous matrix as shown in Fig. 4(a) and (b). The formulation containing no enzyme $(\mathrm{C} 00)$ presented a much denser matrix, while in S05 many micropores can be seen. These pores, generated due to the release of hydrolised molecules of starch to the solution, could be filled by hydroxyapatite (in vitro) or bone (in vivo), leading to a strong bonding of the cement to the bone. Due to this micropores generation, it would be reasonable to expect a decrease in mechanical properties as a function of time of immersion and concentration of enzyme. This was in fact observed, as Table II demonstrates for the first weeks of degradation. While the initial mechanical properties of the formulations containing enzyme were similar (or even better) than those of the control sample, a very different picture was 

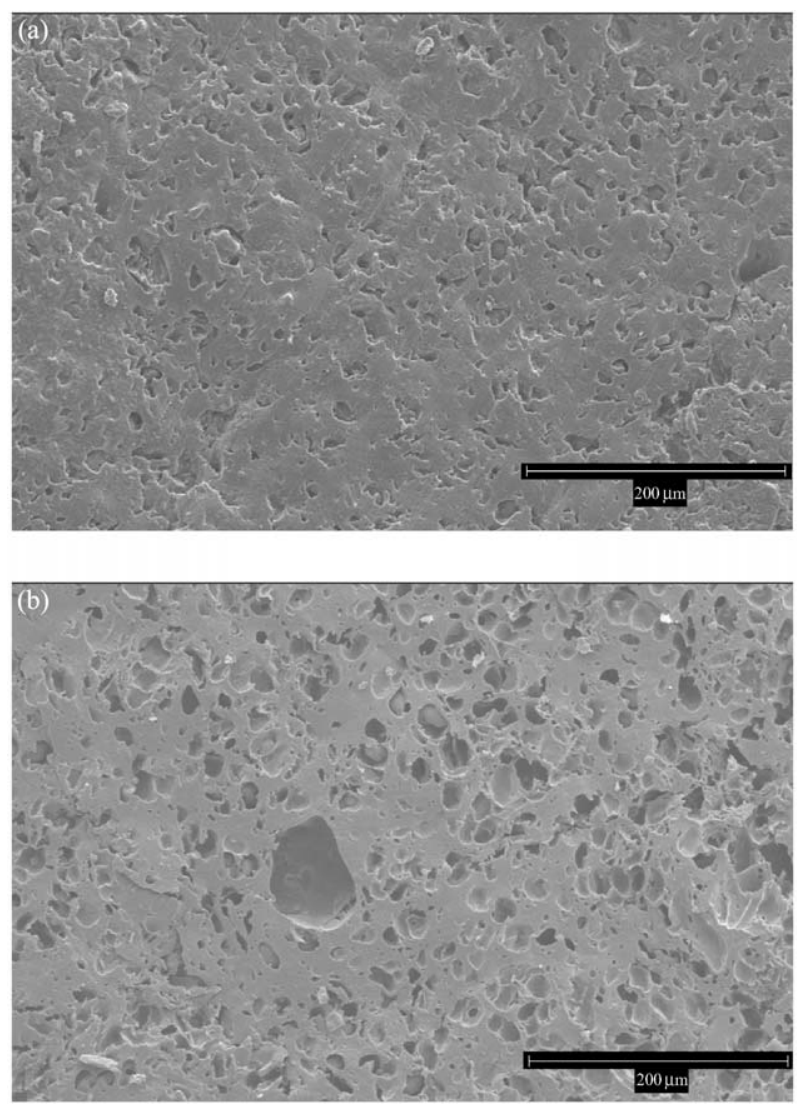

Figure 4 SEM micrograph of specimens after eight weeks of immersion in PBS. (a) C00 (control sample), (b) S05.

T A B L E I I Mechanical properties of the formulations

\begin{tabular}{lllllllll}
\hline & \multicolumn{2}{c}{ Initial } & & \multicolumn{2}{c}{ After 1 week } & & \multicolumn{2}{c}{ After 2 weeks } \\
\cline { 2 - 3 } Sample & $\sigma_{y}(\mathrm{MPa})$ & $\mathrm{E}(\mathrm{GPa})$ & & $\sigma_{y r}(\%)$ & $E_{r}(\%)$ & & $\sigma_{y r}(\%)$ & $E_{r}(\%)$ \\
\hline C00 & $32.2 \pm 6.3$ & $1.02 \pm 0.037$ & - & - & & 89 & 91 \\
S05 & $36.9 \pm 6.2$ & $1.37 \pm 0.084$ & & 68 & 48 & & 58 & 50 \\
S10 & $32.4 \pm 1.9$ & $1.27 \pm 0.22$ & & 65 & 36 & & 52 & 28 \\
\hline
\end{tabular}

$\sigma_{y}=$ yield stress; $E=$ secant modulus at $1 \%$ strain; subscript $r$ means residual mechanical properties, expressed as a percentage of the initial values before degradation.

observed after degradation. The secant modulus and yield stress did not change very much for the control formulation and after two weeks their values were around $90 \%$ of the original (before immersion) values. On the other hand, the stress, and especially modulus, decreased considerably for the samples with enzyme, showing that these parameters can also be used to detect the degradation of the material: the higher the $\alpha$-amylase content, or the longer the degradation time, the stronger the decrease in the mechanical properties.

\section{Conclusions}

In this paper, a novel hydrophilic bone cement formulation possessing a range of interesting properties is proposed. Due to its hydrophilicity, this material is highly bioactive and easily degraded by amylolytic enzymes. However, the water affinity alone is not enough to determine wether or not a material is suited for the proposed application, as AA, which is even more hydrophilic than HEMA, originated formulations which are only poorly bioactive. By tailoring the rate of apatite layer nucleation/growing (through incorporation of different types and amounts of bioactive particles) and degradation kinetics (through incorporation of different amounts of $\alpha$-amylase), it should be possible to match the time scale of both phenomena and obtain a bone cement which bonds strongly to bone. These types of systems might be very useful clinically in the orthopaedic field.

\section{Acknowledgments}

The authors acknowledge Dr I. H. Pashkuleva for helping in the preparation and purification of the chemicals used in this study and Dr H. S. Azevedo for helping on the design and analysis of the degradation studies. L. F. Boesel also acknowledges Fundação Coordenação de Aperfeiçoamento de Pessoal do Ensino Superior (CAPES - Brasília, Brasil) for the Ph.D. grant. This work was partially supported by FCT (Foundation for Science and Technology), through funds from the POCTI and/or FEDER programmes.

\section{References}

1. E. P. LAUTENSCHLAGER, S. I. STUPP and J. C. KELlER, in "Functional Behaviour of Orthopaedic Biomaterials Vol II: Applications', edited by P. Ducheyne and G. W. Hastings (CRC Press, Boca Raton, 1984) pp. 87-119.

2. S. SHINZATO, T. NAKAMURA, T. KOKUBO and Y. KitA MURA, J. Biomed. Mater. Res. 59 (2002) 225.

3. E. J. HARPER, M. BRADEN and W. J. BONFIELD, J. Mater. Sci.: Mater. Med. 11 (2000) 491.

4. L. F. BOESEL, J. F. MANO and R. L. REIS, ibid. (2003). Accepted for publication.

5. C. S. PEREIRA, A. M. CUNHA, R. L. REIS, B. VÁZQUEZ and J. SAN ROMÁN, ibid. 9 (1998) 825.

6. I. ESPIgARES, C. ElvirA, J. F. MANO, B. VÁZQUEZ, J. S AN ROMAN and R. L. REIS, Biomaterials 23 (2002) 1883.

7. M. E. GOMES, A. S. RIBEIRO, P. B. MALAFAYA, R. L. REIS and A. M. CUNHA, ibid. 22 (2001) 883.

8. R. L. REIS, A. M. CUNHA and M. J. BEVIS, Med. Plast. Biomater. 4 (1997) 46.

9. P. B. MAlafaya, C. Elvira, A. GAllardo, J. SAN ROMÁN and R. L. REIS, J. Biomater. Sci. Polym. Ed. 12 (2001) 1227.

10. C. ElVira, B. LEVENFELD, B. VÁZQueZ and J. SAN Román, J Polym. Sci. A: Polym. Chem. 34 (1996) 2783.

11. T. K. Ghose, Pure Appl. Chem. 59 (1987) 257.

12. L. F. BOESEL, M. H. V. FERNANDES and R. L. REIS, J. Biomed. Mater. Res. B: Appl. Biomater. (2004) (in press).

Received 4 October

and accepted 10 October 2003 